\title{
Collaboration for Improving Social Work Practice: The Promise of Feminist Participatory Action Research
}

Affilia: Journal of Women and Social Work

I-19

(C) The Author(s) 2020

Article reuse guidelines: sagepub.com/journals-permissions DOI: $10.1177 / 0886109920954424$ journals.sagepub.com/home/aff (SAGE

\section{Holly Johnson' $\left[\right.$ and Catherine Flynn ${ }^{2}$}

\begin{abstract}
Feminist research and participatory action research (PAR) share the belief that research should directly serve social justice aims and work to alleviate suffering of marginalized and oppressed people. This article presents the results of a unique feminist PAR (FPAR) approach to designing and implementing an evaluation of an intervention with women who have used violence. The site of our analysis is the steering committee that oversaw this work and the extent to which members adhered to FPAR principles. Over the two decades since feminist critiques of PAR began to emerge, new discourses of collaboration have appeared. As researchers, we must be alert to FPAR discourses that mask ongoing hierarchies. Our findings suggest that, while reflexivity and genuine commitment to collaboration are fundamental to enacting FPAR principles, social workers nevertheless face real challenges confronting structural barriers that impede anti-oppression goals. This study highlights the challenges of adhering faithfully to feminist participatory principles in real-life settings and the need for future research to examine the effectiveness of FPAR processes in achieving authentic collaboration among committee members who are chosen to represent disparate perspectives and are backed by vastly different levels of social and institutional power.
\end{abstract}

\section{Keywords}

feminist research, participatory methods, program evaluation

Participatory action research (PAR) and feminist research have complementary goals. Both aim to empower marginalized groups and to affect social change. Both do so by documenting lived experiences and concerns of marginalized groups, naming oppressions, and illuminating subjugated knowledges (Gaventa \& Cornwall, 2008; Hesse-Biber \& Leavy, 2007). PAR approaches that are explicitly feminist PAR (FPAR) aim to empower women to address gender and other

\footnotetext{
' Department of Criminology, University of Ottawa, Ontario, Canada

${ }^{2}$ Département des sciences humaines et sociales, Université du Québec à Chicoutimi, Quebec, Canada

Corresponding Author:

Holly Johnson, Department of Criminology, Faculty of Social Sciences, University of Ottawa, Ottawa, Ontario, Canada KIN 6N5.

Email: hjohnson@uottawa.ca
} 
intersecting inequalities. A major preoccupation in the emerging FPAR literature is the struggle for true collaboration among stakeholders who are brought together to represent widely disparate viewpoints and are backed by different levels of personal and institutional power. Those who strive to exercise FPAR principles must be alert to barriers to authentic communication between university-trained researchers, social workers, and marginalized women and must continually challenge assumptions that these can be fully mitigated by participatory processes.

This article presents the results of a unique FPAR approach to designing and implementing an evaluation of an intervention with women who have used violence. The site of our analysis is the steering committee that oversaw this work and the extent to which members adhered to FPAR principles. We employed two lines of enquiry. By observing meetings of the steering committee, we were able to examine, as outsiders, group members' interactions as they were unfolding. Because observations cannot reveal motives, intentions, or feelings behind actions, we also conducted in-depth interviews with steering committee members as a second line of evidence and a check on our observations.

In this article, we first describe the site of our analysis, then present the theoretical foundations of FPAR and the methods used to evaluate the extent to which the steering committee adhered to FPAR principles, before presenting our findings. This study found that breaking down power relationships is essential to ensuring authentic participation that will yield benefits to very vulnerable women, but this continues to be a challenge in the evolution of FPAR as a research method.

\section{Site of Analysis}

The intervention for women who have used violence was developed in 2009 in the Canadian province of Quebec using a feminist intersectional analysis (Mehrotra, 2010; Samuels \& Ross-Sheriff, 2008). It was designed collaboratively by two women's organizations ${ }^{1}$ and two university-based researchers and has at its core women's abuse and trauma histories and the wider sociocultural context of gendered inequalities (Damant et al., 2018; Roy et al., 2019). In keeping with their feminist intervention and research principles, the program designers were committed to FPAR as a method for developing and implementing an evaluation of the program.

Steering committees offer an important site of analysis for the examination of FPAR principles in action because of the decision-making role that such groups play. Steering committees bring together multiple stakeholders who are expected to participate on equal footing while representing their constituencies in the development of the research project. In this study, a steering committee was set up to oversee the development and implementation of tools for assessing the intervention's effectiveness. The committee was comprised of eight members including two academic researchers, three representatives of women's organizations, a service provider who had been trained to deliver the program in her organization, a woman who had experienced the intervention to address her use of violence, and a doctoral student involved in the research. Each brought to the project different backgrounds and areas of expertise, prior connections to one another, and social and institutional power. By examining the interactions of steering committee members in real time, the current study contributes to the evolving FPAR discourses on authentic collaboration.

Before presenting the results of the evaluation of the workings of this committee, we provide an overview of the theoretical foundations of feminist-based PAR and the method used to assess the committee's fidelity to FPAR principles.

\section{FPAR}

PAR emerged to challenge positivist approaches and their hierarchal, often dehumanizing, structures and relationships. In positivist approaches, researchers set priorities, determine the questions of 
importance, control the methods and processes, and decide what data would be generated and how it would be used (Maguire, 1996; Reason \& Bradbury, 2008). Knowledge emerging from these types of approaches often reproduced inequalities and had limited direct benefit to the people being studied (Joyappa \& Martin, 1996). In principle, participatory feminist researchers reject the positivist tendencies to grant exclusive power to the researcher who, at arm's length from their objects of study, are credited for discovering universal truths. Instead, participatory researchers seek to share control of the research processes with participants and to empower individuals and communities with knowledge and tools to expose diverse social realities and to work toward social change. Epistemologically, the positivist position is empiricist or realist, believing that social reality exists independent of awareness of it and, given the right tools, it can be objectively measured. This contrasts with interpretive perspectives, such as PAR, which maintain that while material realities help shape perceptions, individual experiences and sense-making are mediated by culture, language, and discourse thus producing multiple realities that are capable of shifting over time and place (Ramazanoglu \& Holland, 2002).

Participatory research is political and, unlike positivists who presume researcher neutrality, PAR works in solidarity with marginalized people to alleviate suffering (Maguire, 2007). PAR strives to engage participants meaningfully in all aspects of the design, implementation, and analysis of the research project through reflective dialogue, thus recognizing the capacity of oppressed people to be active agents of change rather than simply recipients of change made by more knowledgeable others on their behalf. PAR methods aim to create space for collective and individual reflection from which new understandings can emerge; this new knowledge forms the basis for action to improve social conditions and human welfare (Reid et al., 2006). Colearning and development of critical consciousness occur as researchers and participants analyze structural causes of problems. People become aware of, and start to believe in, their capacity to make transformative change through acquiring information, skills, and experience via critical analysis of the structures, discourses, and relations that shape their powerlessness (Joyappa \& Martin, 1996).

Feminist researchers share philosophical links to PAR in their belief that research should directly serve social justice action (Joyappa \& Martin, 1996). Although there is no universally accepted definition of feminist research, Ramazanoglu and Holland (2002, p. 146) contend that the aim of doing research from a feminist perspective is "to give insights into gendered social existence that would otherwise not exist" and to produce knowledge for transformation of gendered injustices. The goals of feminist researchers are to challenge multiple and intersectional systems of power and enact solutions to problems that affect women's lives in all their diversity. Rejecting a focus on undifferentiated "women," current approaches incorporate gender with interconnected markers of identity, such as race, ethnicity, immigration, colonization, sexuality, ability, age, and income that interact dynamically with hidden social and structural institutions of power that define and shape lives, and to work toward change based on these real-life experiences (Reid \& Frisby, 2008).

Both feminist and participatory research have "transformative and liberatory intentions" yet gender relations were originally marginalized in PAR leaving women's lived realities ignored or hidden behind an androcentric filter (Maguire, 1996, p. 108). While participatory research highlights power in the social construction of knowledge, feminist research calls attention to the centrality and manifestations of male power and privilege. It was feminists who incorporated "the multiplicity and interconnectedness of oppressions that include gender" into the alternative ways of seeing the world promised by participatory research (Joyappa \& Martin, 1996, p. 113). Feminist PAR means transforming spaces in ways that promote real power sharing and counter gendered, classed, and racialized power relations (Maguire, 1996; Ponic et al., 2010). While feminist critiques of androcentrism across the spectrum of research methods have gradually rendered women less invisible and depictions of gender relations more accurate (Hesse-Biber \& Leavy, 2007), FPAR is set apart by the concerted power shifting in the production of knowledge. Power and avoiding abusing power in 
relationships is a key concern of both FPAR and social work research and practice; it is thus an ideal approach for the study of social work concerns (Hulko, 2015).

Feminist principles are not always easy to put into practice, however. FPAR demands a reflexive process where researchers and other participants are aware of their own shifting power and how it affects relationships with others, are open and explicit about it, and work to mitigate its influence over the research process. This might involve, for example, naming unearned privilege and providing space for counter-hegemonic narratives to emerge (Botha \& Hay, 2016; Hulko, 2015). Maguire (1996) was an early advocate for "more feminist" PAR, claiming that

there is no way to challenge power relationships within the research process-for example, power between the researcher and the researched-without also being intentionally self-conscious of our own behavior in our social relationships, each of which have power dimensions. (p. 112)

As FPAR continues to evolve, it is now recognized that every aspect of the research processfunding decisions, academic and organizational support for certain lines of inquiry, methodologies and research outcomes, and selection of research partners - is infused with power that shifts according to prevailing political influences (Ali et al., 2007). Furthermore, researchers are accountable to funders, their universities or other employers, professional associations, and ethics boards. Combined with the added pressures to publish, all of these factors can affect the autonomy of researchers and true power sharing with research participants (Hulko, 2015). All of these dimensions affect the institutional and personal power steering committee members bring to an FPAR project.

It has been over two decades since feminist critiques of PAR began to emerge. Since then, new discourses of collaboration have appeared. Yet, as researchers, we must be alert to FPAR discourses that mask ongoing hierarchies. This study investigates to what extent the developing discourse of FPAR is being applied in practice and with what effect. Research grounded in feminist and PAR principles commonly is guided by committees comprised of representatives of various stakeholders in order to bring multiple viewpoints to bear on the direction and implementation of the research endeavor. This may give the appearance of collaboration while hiding hierarchies that make it impossible to fully incorporate FPAR principles (Langan \& Morton, 2009). Whitmore (1994) asserts that in communicating with researchers, there is a natural tendency for participants from oppressed groups try to protect themselves from who they see as state-aligned professionals with power over them by saying what they think the researchers want to hear and that profound class, cultural, and racial differences in sense-making means that researchers can never entirely understand the world occupied by the most marginalized people. Furthermore, authentic collaboration is a struggle for researchers and others who, although committed to social justice and sincere about giving voice to powerless people, are trained in more traditional methods with competing assumptions about who controls the research process and who is permitted to challenge this control. Such assumptions can give rise to conflict when group members have conflicting expectations about what is meant by participation and collaboration. Aspects of the research methods may also have to be altered to meet the demands of ethics boards, leading to resentment if collaborators perceive that academic researchers are uncritically using their institutional power.

Researchers, feminist advocates, and service providers live in different worlds with divergent expectations of their roles, rights, and responsibilities as they struggle to negotiate solutions to the problem under study. If the institutionalized privileges and inequalities that accompany these roles are not stated and discussed, true FPAR will be elusive and power relations may be further entrenched (Kohler Riessman, 1987). In addition, long-standing relationships between members can inadvertently enable cliques or alliances to form if they have preestablished ways of working. Some members may not be fully aware that they defer to others who are considered in other contexts to have superior knowledge or expertise and expected ways of relating. These and other aspects of 
power pose challenges for researchers committed to feminist participatory principles as well as social work practitioners who must be vigilant about identifying and revisiting them throughout the research process.

\section{Evaluating FPAR Processes}

Before presenting the results of the evaluation of the committee's working, we tie together the philosophical foundations of feminist-based PAR and the tools we have selected for assessing the validity of the FPAR processes used in this study.

Researchers aiming for transformative social science have opportunities to think creatively about how they undertake to assess the quality of their work (Ozanne \& Saatcioglu, 2008). Reid and Frisby (2008) propose dimensions of FPAR that are useful for assessing the quality of those projects: centering gender and women's diverse experiences while challenging forms of patriarchy, accounting for intersectionality, honoring voice and difference through participatory research processes, exploring new forms of representation, reflexivity, and honoring many forms of action. In this study, we apply these dimensions to better understand the role of steering committees in implementing FPAR principles.

We operationalize these dimensions through types of validity action researchers employ which are congruent with the underlying assumptions and goals of PAR. Ozanne and Saatcioglu (2008, p. 426) list five types of validity: outcome, democratic, process, catalytic, and dialogical validity. Outcome validity is fundamental to the end goal of generating useful knowledge and awareness for improving social life. Democratic validity refers to "the extent to which relevant stakeholders in the problem participate deeply and fully in the research and the extent to which their perspectives and needs inform solutions" (Ozanne \& Saatcioglu, 2008, p. 426). Researchers fail to achieve democratic validity when they do not incorporate diverse perspectives and interests. Process validity is concerned with the ways in which problems are investigated and the extent to which this allows for ongoing reflection, learning, and development of capacities (p. 427). Process validity can be affected by the research setting and the ability of the researchers to develop trust and rapport among participants. Examination of these processes helps identify threats to democratic validity and to the extent to which processes permit problems to be investigated in a way that everyone is able to develop capacities and multiple perspectives can emerge (p. 427). If the research participants are not motivated to understand and change social conditions as a result of knowledge generated by participation in the study, catalytic validity is not present. Dialogic validity relates to critical debates with outsiders to the research study who will challenge the explanations, assumptions, weakness, and actions resulting from the study.

These criteria for validity in action research are consistent with the values of social justice, solidarity, and democracy so important to feminist researchers and to social work, in particular structural social work, a practice which interrogates and endeavors to dismantle oppressions equally in society and in intervention approaches (Mullaly, 2007). Structural social work proposes to establish egalitarian relationships with user services and elevate the personal and political power of participants thus strengthening their capacity to improve living conditions and transform oppressive social structures (Mullaly, 2007).

Democratic and process validity are the sole focus of this study's evaluation of the work of the steering committee. Outcome validity, in this context, pertains to the production of the research tools (questionnaires and semistructured interview guides) used to evaluate the effectiveness of the intervention, and these were accomplished by the steering committee. We are concerned with the processes undertaken by member of the committee to produce these research tools and not the tools themselves. The conditions to examine catalytic and dialogical validity were yet to occur and thus 
were beyond the scope of this analysis. The data collection grid in the following section shows how each parameter of democratic and process validity was operationalized for this project.

\section{Method}

The steering committee, whose task was to develop tools to evaluate an intervention for women who had used violence, was made up of eight members. Initially, the committee was comprised of two academic researchers who had developed the intervention and two representatives of women's organizations, one of whom had requested the intervention. Additional members were recruited according to their affiliation and interest in the intervention and this evaluation. One of the academics recruited a doctoral student whose dissertation focused on the evaluation of the intervention and the women's group representatives recruited the remaining three members: a colleague, a service provider who delivered the program, and a woman who had participated in the program to address her use of violence.

The composition of the steering committee was relatively homogeneous on markers of identity. Social status and role identification were the primary overt identities: University professors are awarded status higher than women's groups or recipients of social work interventions, and the role of service provider likewise carries status over women receiving interventions. Some sexual diversity was represented although not openly disclosed and only one committee member belonged to both an ethnocultural minority and a sexual diversity group. She was in a position of unequal power to her academic supervisor, who was also a member of the committee, a relationship that is backed by institutional norms and not easily challenged. The collaborative workings of this group and adherence to FPAR principles were the focus of our analysis.

\section{Data Collection}

The analysis presented in this article is based on two data-gathering strategies that are interwoven and complementary. First, each of the seven meetings of the steering committee between 2014 and 2016 was subject to observation by the authors who followed an observation grid based on Ozanne and Saatcioglu's (2008) parameters for assessing the effectiveness of PAR processes through democratic and process validity. Observation is a method used in qualitative research to view events and actions as they occur and within social context, and to learn what people do, not just what they say they do (Neuman, 2009). In this project, nonparticipant observation was carried out as unobtrusively as possible (Ciesielska et al., 2018). Six meetings took place in person and one by videoconference. At the six in-person meetings, we evaluators were set up at the furthest point possible behind steering committee members who were positioned in a square, with the intent that members would not be reminded that they were being observed and would be at ease to act naturally (Ciesielska et al., 2018). Feminist community partners on the steering committee initially expressed discomfort with this positioning, having been accustomed to seeing all research team members around the table, in an open and transparent conversation. We explained that we were not present as team members and that it was important for the sake of our independence that we avoid being drawn into discussions or reacting through body language or obvious note-taking. Very quickly in the first meeting, steering committee members ignored us and did not refer to us or attempt to engage us in discussions.

Table 1 displays the grid used by the evaluators to assess the various parameters of democratic and process validity as outlined by Ozanne and Saatcioglu (2008). For democratic validity, the grid included indicators and contra-indicators related to equal participation of members, power relationships among members, collaborative decision making, consensus-building, and recognition and respect for each member's expertise. Process validity was evaluated according to indicators and contra-indicators concerning the extent to which committee meetings were a site for learning and 
Table I. Observation Grid.

Concept Indicator

Democratic validity

I. All members participate equally

Process validity

I. Committee meetings are a site for learning and for improving practice

2. Members participate equally in all phases of the committee's work

3. Members participate meaningfully in processes of reflection that leads to action

4. Members work collaboratively to arrive at solutions together

\section{Critical reflection is encouraged} and assumptions are challenged
Members exert equal power; opinions and knowledge are equally respected

Counter-indicator: Some members are shown deference, there are assumptions of authority, certain knowledge is privileged, cliques are tolerated

All members are encouraged to voice opinions; expertise is recognized and respected

Counter-indicator: Some members are afforded more time to speak, no attempt to hear from all equally

Decisions are made in committee meetings in collaborative fashion

Contra-indicator: Decisions are made outside of meetings by certain members, others don't have meaningful input, diverse opinions are not considered

Decisions are formed by consensus

Counter-indicator: Decisions are made by majority vote or by members with more authority, status, or power; attempts are not made to arrive at consensus

Members are open to learning through respectful listening and reflecting on the points of view of others; members sometimes alter their perspective after considering other points of view Contra-indicator: Members are not open to hearing the views of others, are not oriented toward learning from others, are dismissive or not genuinely interested in the views of others

Members attend all committee meetings and participate in discussions. Members encourage full participation of others, actively seek out other points of view. Members do not hesitate to take on work that would benefit the committee.

Contra-indicator: Some members are shut out (excluded) from certain discussions based on perceived areas of expertise or other factors. Members do not participate in all phases of the work or their contribution is minimal

Members listen to and reflect on other points of view, the work of the committee leads to concrete results, meeting time is spent productively

Contra-indicator: Time is not spent productively, goals are not met, and members are not meaningfully engaged

Members show respect for the opinions of others, work in a spirit of collaboration toward agreed upon goals, members actively look for solutions

Contra-indicator: Members show lack of respect for others, weak commitment toward goals

Members are free to challenge assumptions. Challenges are made respectfully, the chair and others seek out diverse opinions Contra-indicator: There is a level of discomfort or censure when challenges or critical reflection is raised, members cease to raise challenges, diverse opinions are not raised 
Table I. (continued)

\begin{tabular}{|c|c|}
\hline Concept & Indicator \\
\hline $\begin{array}{l}\text { 6. Committee meetings provide a space } \\
\text { where strengths and knowledge are } \\
\text { valued and respected and members } \\
\text { are empowered }\end{array}$ & $\begin{array}{l}\text { Members show respect for the knowledge and experience } \\
\text { of others; members are empowered to share their knowledge } \\
\text { and experience } \\
\text { Contra-indicator: Members show disrespect or lack of interest } \\
\text { in the knowledge and experience of others; members are not } \\
\text { invited to share their knowledge }\end{array}$ \\
\hline $\begin{array}{l}\text { 7. Committee meetings provide a space } \\
\text { where members can openly reflect } \\
\text { on and critically analyze practices } \\
\text { and behaviors }\end{array}$ & $\begin{array}{l}\text { Members create a safe space for open reflection. Diverse } \\
\text { perspectives are heard and discussed in a respectful manner, } \\
\text { members are able to reevaluate practices and behaviors } \\
\text { Contra-indicator: Critical analysis or challenges to establish } \\
\text { practice is not encouraged or is actively avoided or shut down }\end{array}$ \\
\hline $\begin{array}{l}\text { 8. Committee meetings provide a space } \\
\text { where ideas and assumptions are } \\
\text { tested and deconstructed }\end{array}$ & $\begin{array}{l}\text { Members are able to question assumptions and test out new } \\
\text { theories or ideas. } \\
\text { Contra-indicator: Questioning ideas and assumptions is not } \\
\text { encouraged or is actively avoided or shut down }\end{array}$ \\
\hline
\end{tabular}

improving practice, attendance and participation at meetings; actively seeking out others' points of view, respect for cycles of reflection and action, openness to critical thinking and challenging assumptions, and collaboratively seeking solutions. At each meeting, we completed the observation grid separately and later merged them. The separate impressions showed a common interpretation of the observed situations. In the rare cases where we evaluators had different interpretations of a particular situation, these were discussed in order to arrive at a consensus.

As a second, complementary line of evidence, once the committee meetings had ended, we met individually with seven of the eight steering committee members for a semistructured recorded interview. All members of the steering committee were interviewed with the exception of one agency representative who was unavailable because of work pressures. The purpose of these interviews was to obtain confidential feedback from members on their views of the functioning of the steering committee and served as a check on the observations. Members were invited to share their views on the following:

1. What was your understanding of your role on this committee when you were invited to join?

2. Have you been able to participate in the ways you expected or wanted to? If not, can you tell me more about that? If so, what made that possible?

3. Do you feel your participation was meaningful? By that I mean were you able to freely express your opinions and ideas, were you able to influence decisions? Can you give me an example?

4. Did you feel like an equal partner? Do you think other members of the committee were treated as equals? Or were there hierarchies where some members had more power than others?

5. Was there space for critical reflection? Was there a space to challenge common assumptions?

6. In your opinion, is this process/structure a good one for creating positive social change? Can you give me an example?

7. Was there anything in particular that made this a positive experience for you? Anything that made it a negative experience?

8. Is it something you would like to do again if you had the opportunity?

These open-ended questions allowed interviewees to expand on responses as they wished and allowed us to follow strands of the conversation that strayed from the questions. 
We were concerned that our professional and personal relationships with various members of the committee may affect disclosures. One of us shared the same academic supervisor as the doctoral student and had collaborated on a separate research project. The other had a previous participatory research collaboration with one of the academic members which was nonhierarchical in the sense that neither were principal investigator of the project. We separated the work so that the interviews with the researchers and the research assistant were conducted by one of us and interviews with the participant of the program, and the community partners were conducted by the other. This strategy was used to reduce social desirability effects, conflicts of interest, and reproduction of power relationships. Prior to beginning the observations, approval was obtained from our own research ethics boards and those of the academic researchers on the committee. Each committee member signed a form indicating their consent to be observed and interviewed and to be cited without attribution. All committee members, with the exception of the academic researchers and doctoral student, received an honorarium for their participation. This was intended to compensate agency representatives for time away from their work and the program participant for transportation, childcare, and other expenses.

\section{Data Analysis}

A thematic content analysis process was conducted with Microsoft Word and was used to codify the observation grids (Miles \& Huberman, 1994). Our observations were guided by indicators and contra-indicators of both democratic and process validity, and we used these observations to form analytical categories. The possibility of adding emerging categories was left open. For example, we had not initially planned to document the leadership qualities of the person nominated to chair the meetings. However, it soon became evident that this role was pivotal for the democratic validity of the project and was therefore added as an indicator along the way. We then similarly coded interviews and analyzed whether they supported, confirmed, or contradicted the observations. In the context of a small team where the roles of each were relatively specific, anonymity and confidentiality are difficult to protect. For this reason, we extracted from the quotations all information that could potentially reveal the identity of the interviewees and did not link quotations to specific individuals (e.g., researcher \# 1, community partner \# 3). The results of this analysis are presented below.

\section{Results}

\section{Democratic Validity}

Democratic validity depends on full and active participation of relevant stakeholders in the research process and the incorporation of diverse perspectives in the search for solutions (Ozanne \& Saatcioglu, 2008, p. 426). From the outset, our analysis showed how democratic validity was weakened because of the lack of diversity among committee members, apart from status roles, where we observed little sexual or ethno/cultural diversity. One individual identified as a sexual minority woman and another as a member of both an ethic and sexual minority. Importantly, the presence of just one program participant in the discussions meant that full and active participation of relevant stakeholders and incorporation of diverse perspectives was missing. Just one graduate student, one member representing women who had experienced the intervention, and one who had delivered the intervention cannot represent the possible diverse perspectives of women in these positions.

Although the committee lacked diversity, our observations and in-depth interviews also uncovered instances where democratic validity was strengthened. This included, for example, evidence of 
equality of participation and respect for individual member's expertise; the breaking down of hierarchies and power relationships; and the encouraging of consensus-building and collaborative decision making. One example of decision making by consensus occurred early in the project, where the steering committee undertook to devise a name for the intervention. A discussion of nearly an hour took place to designate a meaningful name that would accurately identify the goals of the program without stigmatizing the women participating. A headline title as well as a different action verb encompassing the intervention was eventually selected by the committee from among a set of key words. We observed how steering committee members brainstormed and made sure each time that everyone agreed on the meaning of each word and its relevance to the program. The discussion took place in a positive, lighthearted atmosphere and the name Violente, moi? Explorer, décider, agir autrement. Un programme adapté pour mieux intervenir auprès des femmes qui exercent de la violence (Me, violent? Explore, decide, act otherwise. A program to improve responses for women who use violence) was eventually chosen through the active participation of all committee members in the search for a solution.

Committee members came to the table with different areas of expertise as a function of their lived experience, knowledge, and training. As evidence that members' expertise was recognized and respected, we observed many moments when the chair tried to ensure that all members had the opportunity to provide input into the discussion. At times, it was part of a formal roundtable, and at other times, members who were less likely to speak out were invited to do so. In this context, the role of the chair was crucial, particularly at the beginning of the project, when some members appeared to be less comfortable offering their opinion spontaneously, a reticence that decreased noticeably over time. We observed an effort on the part of the chair to put the more reticent members at ease and to invite but avoid pressuring them to speak. Early displays of discomfort may have been due to uncertainty over expectations of role performance for those unaccustomed to direct involvement in research projects or whose past involvement was in the form of a one-time consultation not guided by FPAR principles. One committee member expressly said in the interview that she felt some committee members had difficulty finding their place, which led her to reach out and invite others to participate.

Throughout the span of seven steering committee meetings, when members voiced their opinions, they appeared to be received with respect and attention, regardless of their position on the committee. Our observations were corroborated in the interviews:

I felt that members of the committee had confidence in me (...) I know that when I spoke I brought opinions that were very well received (...). I always felt equal among equals.

Similarly, another stated:

I could give my opinion( ... I I wasn't ... I wasn't a researcher or anything ... as soon as I said anything, the researchers $(\ldots)$ considered me equal to the others.

At the same time, one member who realized that she had more power in the group described the conscious effort she made to listen and make space for others who may have hesitated to share their views:

I had to work on myself because one difficulty I have is not to interrupt and speak my mind. I try but I don't always succeed.

Here, we see how this woman was aware of the need to avoid dominating the conversation to allow other perspectives to emerge. We sometimes observed a split in the group between the academic researchers and other members that could be interpreted as deference to those nominally 
"in charge" and the maintenance of power hierarchies. These observations were corroborated by the interviews where a certain hierarchy was identified by committee members, despite an observed intention to level power relations and solicit the participation of all. As one participant explained:

With respect to intention, ( . . ) everyone was considered an equal member and I think there was a concern to include everyone $(. .$.$) at the beginning we didn't know how this equality would materialize$ (... ) but in fact, I think there was still a hierarchy, and I think the two principal researchers still had more power than the others.

In the interviews, other committee members likewise identified the power of the researchers. This power was manifested in the authority related to the researchers' management responsibilities and accountability to funders and their universities, as well as their broad knowledge and experience in leading social science research. However, this was stated less as a criticism and more as acknowledgment of the responsibilities researchers have for ensuring projects adhere to requirements set by universities, ethics boards, and funding agencies and may reflect preestablished ways of relating and deferring to academic expertise. As one participant stated:

For sure concerning knowledge ... it's the researchers who are leading the project ( ...) they had a lot of knowledge and at times (...) I didn't feel that they had more power than I did but they had more knowledge (...) it's (names of researchers) who decided what they brought back (to the committee).

This participant makes an interesting distinction between knowledge and power and hesitates to recognize that the knowledge the researchers had to shape the project and their ability to decide what information to share with the committee are actions imbued with power. Another committee member shared this:

Power? Well the two researchers, that's for sure ... (...) It's power to never think of having a meeting without (names of researchers) being there but we can certainly have a meeting without me. That means a difference in power. It's not a criticism, it's an observation. I think we have to recognize that the two researchers in this case had power different than the others and that's fine.

In the following quotation, the participant asserts that the researchers' power and influence over the project does not manifest in a "relational hierarchy," In other words, power over others.

The role of the researchers ... they manage the research processes, the financial resources, the human resources. It's not a relational hierarchy. The researchers have more power, certainly more influence. That goes with the role. Is that negative?

These participants were willing to concede certain influence over the project to the academic researchers as an expected part of their role as administrators of the project. The traditional role of academic researcher within the research process thus was not completely challenged, and other committee members seemed willing to overlook the unequal power held by the researchers on account of what were perceived to be mutual respect, listening skills, and a collaborative orientation. This willingness to overlook power hierarchies in light of the researchers' perceived commitment and respect can be seen in the following quotation:

I think (names of researchers) are feminists, committed ... that means we work as a team, that everyone has her opinion, and we debate (...) I didn't feel less than nothing ... sometimes it happens on certain committees where it's not you with the expertise (...) the researchers, we see that they are committed, we saw that it was important for them, my opinion and the opinion of the others.... 
The way in which the researchers showed openness to criticism and to learning was also raised as a positive factor by others:

What I appreciated again with (names of researchers), it really was perfect every time (...) with them I really always felt ... there was never any uneasiness. Whenever I did something it was to improve and they always received it as that, there wasn't any criticism.

Never at any time did I feel that my expertise was not valued (...) Never did I not feel free to speak.

When (name of researcher) gets engaged in a process she is very respectful of that process. Every meeting she is very committed to really doing it.

Our analysis thus showed how demonstrating an openness to constructive criticism was a factor that helped mitigate perceived power imbalances between the researchers and other committee members.

We also observed how the leadership of the committee chair contributed to the democratic participation of all members. There were many instances throughout the meetings where the chair structured discussions in order to build consensus around solutions. The issues raised by the members of the committee were summarized after each item on the agenda in order to obtain a collective understanding of the decision and the chair made sure to reach consensus before changing the subject. An example is when the committee faced some challenges related to the flow of information. The meetings were relatively spaced out in time compared to the rhythm of the research process which made follow-up work more difficult for those on the committee who did not have direct responsibility for data gathering and analysis, which fell to the researchers and the doctoral student. This difficulty was addressed quickly and collaboratively in the first year of the project when the members created a communication tool to facilitate follow-up between meetings.

However, one member whose participation did not increase over time was the woman who had undergone the intervention to address her use of violence, the woman whose lived experience was central to the committee's work. Women's use of violence is a taboo topic, especially among feminists and others who advocate on behalf of women victimized by male violence. This comes amidst well-founded concerns that attention to women's use of violence may add fuel to claims that women are as violent as men in intimate relationships and may reduce support for abused women (Dobash \& Dobash, 2004). In addition, women who receive this intervention may be marginalized in their families and communities for contravening their feminine and maternal societal roles and subsequently have few spaces open to them for sharing their lived realities. Membership on the steering committee provided the potential for one such space to honor her experiences and challenge assumptions, but it was not conducive to her active participation. Increasing the representation of women who had undergone the intervention may have helped to break down these barriers.

Despite honest efforts to equalize power, academics and advocates, who are comfortable and experienced at expressing their opinions and verbally challenging each other, dominated the one program participant who has not had the same opportunities to acquire the language or the knowledge of norms and processes that are germane to the research and advocacy worlds. Reflecting on this limitation, committee members shared:

I found it difficult to find myself the only representative (...) in this category (...) I don't blame anyone (...) but maybe if there had been (someone else) with me, that would have relieved some of the responsibility.

It's good that the women who participated in the program are represented on the committee... and to have succeeded in having one with us is a good thing. But we should have had at least two. 
In sum, our analysis demonstrates how steering committee members were able to participate freely in deliberations and arrived collaboratively at decisions and solutions. Inclusiveness was improved when committee members were actively encouraged by the chair to participate and when individual members worked to equalize power. The nonacademic members identified the researchers as wielding greater power in the group, but they accepted this as a manifestation of the researchers' roles and responsibilities vis-à-vis the funding agency and the universities to which they were affiliated. This deference to the researchers may have been a function of preestablished ways of relating and was considered to have been mitigated somewhat by the researchers' interpersonal skills and commitment to learning and practicing FPAR principles.

We argue that lack of diversity among steering committee members and limited inclusion of women who had experienced the intervention negatively affected the democratic validity of the project. Ethno/ cultural and sexual diversity was very limited, and this affected our ability to analyze deeply how these identities may have influenced group interactions. In the interviews, committee members highlighted institutional status and identity rather than systems of race or sexuality as influencing power relations, which confirmed our impressions acquired through observing the interactions of the group.

\section{Process Validity}

Process validity is achieved when problems are investigated in a way that allows for ongoing reflection and learning and participants are able to develop capacities and improve practice over time. Achieving process validity depends on democratic validity and vice versa. Whereas democratic validity depends on full and active participation of relevant stakeholders and incorporation of diverse perspective in the search for solutions, process validity pertains to the ways through which this active, inclusive participation is achieved. Process validity is strengthened through attendance and participation at meetings, seeking out different points of view, encouraging cycles of reflection and action, demonstrating openness to critical thinking, challenging assumptions, and working collaboratively toward solutions. Overall, our findings uncovered many examples of process validity although there were also situations where opportunities were missed.

Full and equal participation is a thread that runs through both democratic and process validity, and it can be affected by attendance, barriers to open communication, and power differentials manifested in roles and responsibilities. Considering that half of the steering committee members were representatives of nonprofit women's organizations, which are notoriously overtaxed and underfunded, we found that membership on the steering committee was relatively stable, and a high level of commitment to the project was demonstrated by the consistent attendance of the majority of members. The committee was chaired in the initial stages by a longtime representative of a women's organization who left her employment midway through the project and was replaced by a representative of a different women's organization. This represented the sole change in membership on the committee over a 4-year period. The attendance of two other representatives of women's organizations was inconsistent due to problems related to resource and staffing at their respective agencies. The evaluators completed interviews with all members of the steering committee with the exception of one agency representative who was unavailable because of work pressures.

Our analysis showed how a feminist-based PAR process can be considered a place of learning. Each steering committee member appeared committed to processes that provide opportunities for listening and learning from others and for collaboratively seeking solutions to improve practice although this did not always happen. As several of our interviewees described:

At each meeting something happened (...) I felt like we were debating for real.

Sometimes we questioned things ( . . . ) we could be critical ( . . I) I'm speaking for myself but it's true for everyone (...) I felt that's what was expected from us, that the researchers didn't just want us to say yes it's all great. 
However, one individual acknowledged occasions when she failed to challenge comments made by another member, thus missing opportunities for authentic participation, challenging assumptions, and critical self-reflection (both on her part and on the part of the other person). She framed this in terms of her own power over the other member:

We did not always challenge (name of committee member) when we could have, when she said things that demonstrated she didn't understand certain elements or were against certain values the group has. That is not treating her as an equal .... I didn't want to be angry or hurt her feelings, didn't want her to leave the group, didn't want to... use my power.

In her account, this committee member is reflexive about the power that underlies her own social position and her position on the committee. Her use of first-person plural ("we") suggests she was certain she understood (and was in agreement with) the dominant values of the group and suggests she knew the other person was alone in her views, perhaps having discussed these concerns with others ("we did not always challenge... when we could have..."). She then described her discomfort simultaneously at hearing views that she wished to dispute, and at her failure to speak up. She struggled with not wanting to abuse her power by challenging the other person's views in front of the group, and as a result, she recognized that she failed to fully respect the person as an equal. Process validity is affected in instances like this when members do not allow problems to be investigated in a way that allows for the reflection and learning that can occur when different points of view are aired.

Another concern that was raised at a committee meeting early on was lack of communication among members during the long periods between meetings. Committee members responded by collectively developing a process to share updates and progress between meetings, created mechanisms to facilitate the attendance of all members at each meeting (by exhibiting flexibility concerning the location and timing of meetings), and systematically opened up opportunities for input from everyone to ensure collaborative decision making. Nevertheless, the interviews revealed that participation was perceived by some members as unequal at times. This issue was not raised by committee members during meetings, which suggests that, although the committee was a safe space for critical thinking about the tasks at hand (which were to design and implement tools to evaluate the intervention), it was not always a space where members could discuss in a reflexive and critical way the power relations that might affect interactions among members of the group.

As an example, we observed discussions in the initial stages about task distribution among committee members who then provided feedback. There was no further discussion on this topic at committee meetings which left us to assume that everyone was satisfied with their assigned roles at this stage of the project. However, interviews revealed something different.

I think they would have been able to encourage even more critical thinking maybe questioning the roles a little more, questioning the ... relationships between different members a little more ... asking many more questions about the content, about how... what other members think... how can they could contribute... they thought a bit about how the project would go but I think they maybe didn't ask enough questions about our group, about this entity that was our committee, about the power relations within the group.

In this instance, early in the work of the committee when role expectations were uncertain and some members were perhaps hesitant to speak out, an opportunity to challenge assumptions and invite critical thinking was lost.

An example where the group could have better encouraged cycles of reflection and action concerns analysis and publication of results. Knowledge transfer is a critical component of any 
research project, and at the best of times, it is time-consuming and challenging. As this FPAR project progressed, community partners became less involved at the data analysis stage. The researchers and the doctoral student worked behind the scenes between meetings to analyze the results of the evaluation of the intervention and then presented updates at steering committee meetings. Nonacademic members expressed interest in having input into the production of academic journal articles and attendance at conferences where the results of the research project could be disseminated (although they also stated they did not have time to do so). However, for some, their role felt more like providing feedback on a completed analysis rather than an invitation to make a substantial contribution. As these members described:

Maybe we could have been more involved, maybe with the analysis $(\ldots)$ but time was a rare commodity (...) It's like you feel at times ... you get a lot of discussion between (names of researchers) and when it comes back ( . . . you get something that is already decided without benefit of debate. It's not essential but the process could have been altered... But at the same time the climate we were working in, there was listening, so it compensated.

The intellectual reflections, internal debates... we felt at a given moment... and it didn't really bother me but it could have (...) the impression that business happened at another meeting that we weren't at, like the meeting to prepare for this one, and you feel that there have been some interesting debates but then you just have the flat results (...) if I name it, that's how I felt.

In this way, the knowledge mobilization step of the project proceeded more closely according to traditional roles followed by research teams not invested in FPAR processes, which call for ongoing reflection and learning so that participants develop capacities for critical thinking and action.

An important indicator of satisfaction with the FPAR processes utilized in this project is a willingness to participate again in such a process. Despite some concerns about power differentials and lack of opportunity for input at certain stages of the project, all steering committee members said in the interviews that they would welcome a similar opportunity in the future. As they described:

I very much liked this committee ( ...) it's the first time that (...) I felt that what I brought could help (...) I found that they (the researchers) left us plenty of space.

We were not there as decoration just to have a good report at the end.

I always liked being there, there are no negatives (...) Nothing is ever perfect, I'm not saying that the committee was perfect, but we did it together.

I was with super competent people, researchers who I felt recognized what I brought to the table so personally I got something out of it too.

I've participated on many committees and none like this one. It has truly been a pleasure. It functions so well.

It's been very interesting to work alongside research, to see how it works, and to be able to influence it.

I think the idea that it is possible to work with researchers will be brought into other contexts.

These quotations suggest that, despite challenges, many aspects of process validity were achieved. Committee members described feeling able to express divergent points of view, reflect on issues critically, and work collaboratively toward shared goals. Additionally, members were able to develop capacities for research and action that may change their expectations about future interactions with researchers and the outcomes of research and social work interventions. 


\section{Discussion and Conclusion}

This study evaluated the strengths and challenges of feminist-centered PAR. Using observation of group interaction and semistructured interviews with actors involved in an FPAR research process, we assessed the group's fidelity to FPAR principles. We focused on democratic and process validity that are concerned with full and active participation of members, critical reflection, engagement of marginalized people, critical examination of oppressive power relations, and capacity building.

Overall, study participants described their experiences of FPAR as fundamentally different, and more satisfying, than any previous involvement with research, which had felt tokenistic by comparison. Many expressed feeling "equal among equals," that their expertise was valued and respected, and that their contribution had a genuinely positive impact on the processes and the outcomes of the project. Likewise, they demonstrated a commitment to learning from each other, thinking critically about the tasks before them, and actively and routinely seeking out others' points of view to develop consensus around decisions.

On the other hand, the participants in our study also experienced challenges in applying FPAR principles in their work. Some committee members recognized the limited ability of themselves and others to challenge areas of disagreement at times, others felt the distribution of tasks was not fully discussed, and the nonacademic members described having minimal input into dissemination of the results of the research. Members had some success in challenging the power inherent in the role of an academic researcher, but at the same time identified a hierarchy that they attributed to the researchers' responsibilities to universities and funding agencies. Those who spoke about this power imbalance were of the view that the academic researchers' personal communication styles and openness to critical reflection helped mediate the effects of this hierarchy. Alternatively, nonacademic members may have had difficulty challenging role expectations, particularly if these expectations were well established in prior interactions or if members had not previously been in a situation where critique was encouraged.

This study illustrates some of the challenges in putting into practice, through participatory processes, the goals of feminist research to challenge intersecting systems of power and to find solutions to problems that affect women in all their diversity. A major preoccupation of FPAR researchers is finding ways to ensure full and authentic collaboration among group members who are selected to represent a range of stakeholders and who present with disparate levels of social and institutional power. While feminist research aims to be empowering for women, differential power among women can be masked in multiple organizational and structural ways. One limitation to the realization of FPAR principles in this study was the underrepresentation of relevant stakeholders. Only one doctoral student was present on the committee. Not only is it impossible for her to represent others in that position but the presence of her academic supervisor on the steering committee created a power imbalance that is not easily challenged. Moreover, only one committee member represented the point of view of women who underwent the intervention, and just one agency representative had been trained to deliver the program. Lack of diversity in roles and experience limited the extent to which stakeholder interests and concerns could be fully incorporated and placed a burden on each of these women in terms of being able to adequately represent their constituencies. This was particularly the case for the sole member selected for her identity as a woman who had used violence, given the power differential between her and other committee members.

In this study, power and authority ascribed to institutional and social roles remained in some form throughout. Academic researchers have time, knowledge, and resources that women's groups do not and, as we found in the current study, even when honoraria are offered to help compensate for time away from their agencies, representatives of women's organizations were those most likely to be absent from meetings. Furthermore, committee members did not always feel free to discuss, in a 
critical way, power relations affecting group dynamics. This was especially true for the woman with direct experience of the intervention itself, which represents a particular challenge to the realization of authentic FPAR. Women receiving social work interventions are ascribed and may internalize less power and competence, particularly if they suffer from poor economic status and low educational attainment or are stigmatized in their families and communities or by service providers as women who use violence. There is an assumption behind the participatory emphasis in FPAR that, given space and good intentions, all participants will assert themselves on an equal footing with others. In the current study, researchers and service providers on the steering committee had a long history of working together and of public advocacy and debating issues of importance to women. By contrast, the woman who had received the intervention was a newcomer to both this group and to the worlds of advocacy and research. With their extensive histories of state intervention and acute awareness of the decision-making power of authorities, oppressed women who are invited to share their truths encounter barriers to communication that can be mitigated through participatory processes but can these barriers be eliminated entirely (Whitmore, 1994)? Our findings raise questions about the ability of FPAR groups to truly deconstruct social hierarchies grounded in social and professional status. Even within a group that genuinely values and desires equal collaboration, this was difficult to achieve.

Also present were power relationships between steering committee members and the two of us. We took these into consideration in determining how we would share responsibility for the one-on-one interviews. Nevertheless, hierarchies grounded in preexisting relationships can affect future relationships and employment prospects and may inhibit candid or negative assessments of observed behavior. Because of their similar positioning and prior work together, the one evaluator felt some solidarity with the doctoral student and had a long-standing hierarchical relationship with her prior academic supervisor who sat on the steering committee. Aware that relationships established in other contexts could potentially taint the accuracy of data gathering and analysis, due to preconceived ideas or expectations, we were particularly cautious in documenting our observations. This is where cross-verification of observations following each meeting performed a critical check on accuracy. Additionally, it was important to document examples to support the observations in an effort to avoid confirmatory bias that would lead us to search for and itemize actions of committee members that conformed to perceptions established in other settings and interactions.

This study also illuminates an attempt to translate the social work values of empowerment and democracy into practice. In doing so, it raises questions about how to meaningfully include women with experiential expertise in the development and evaluation of social work interventions. Our findings suggest that, while reflexivity and genuine commitment to collaboration are fundamental to enacting FPAR principles, social workers nevertheless face real challenges confronting structural barriers that impede anti-oppression goals. In our attempts to improve social work practice through meaningful involvement of community-based service providers and women receiving interventions, we continually confront institutional and structural power and privilege and real challenges in living up to the ideals of diversity and representation of marginalized women. This steering committee partly achieved the aims of structural social work to establish egalitarian relationships, strengthen the capacity to improve living conditions, and challenge oppressive structures. Our findings show that this a tall order, however. Challenging oppressive social structures requires that we commit to engaging in meaningful and creative ways with the people affected and that we recognize that the best intentions and the opening of participatory spaces is just a starting point to true collaboration.

And finally, our findings highlight the need for future research to examine the effectiveness of FPAR processes in achieving authentic collaboration among committee members who are chosen to represent disparate perspectives and are backed by vastly different levels of social and institutional power, including marginalized and relatively powerless people who are at the center of our social work interventions. Importantly, by both observing group dynamics and interviewing group 
participants in-depth about what they experienced, we were able to conclude that assumptions about equal participation based solely on what we witness may lead to false or incomplete conclusions. Polite interactions frequently mask disagreements or frustrations. This study highlights not only the advantages of an approach in which FPAR processes are observed in real time as they are unfolding; it also demonstrates the importance of interviews for uncovering what is unknowable by observation alone. FPAR offers a framework for ensuring that we are true to anti-oppression intentions in social work practice but only if we remain self-critical and reflexive.

\section{Declaration of Conflicting Interests}

The author(s) declared no potential conflicts of interest with respect to the research, authorship, and/or publication of this article.

\section{Funding}

The author(s) disclosed receipt of the following financial support for the research, authorship, and/or publication of this article: This work was supported by the Social Science and Humanities Research Council (890-2012-0030).

\section{ORCID iD}

Holly Johnson (D) https://orcid.org/0000-0001-5889-7234

\section{Note}

1. The two women's organizations are Relais-femmes, a feminist organization that provides training, research, and consultation and L'R des centres de femmes, which represents 90 women's centers in the Province of Quebec.

\section{References}

Ali, Z., Brown, G., Bywaters, P., du Boula, D., Mirsch, M., Lethery, G., \& Poole, H. (2007). Setting the agenda. In G. Letherby \& P. Bywaters (Eds.), Extending social research: Application, implementation and publication (pp. 69-89). Open University Press.

Botha, C. S., \& Hay, J. (2016). Narratives of adolescent girls journeying via feminist participatory action research through the aftermath of divorce. Africa Education Review, 21(13), 165-180.

Ciesielska, M., Boström, K. W., \& Öhlander, M. (2018). Observation methods. In M. Ciesielska \& D. Jemielniak (Eds.), Qualitative methodologies in organization studies (Vol. II, pp. 33-52). Palgrave Macmillan.

Damant, D., Roy, V., \& Chbat, M. (2018). Réflexions entourant l'impact de la socialisation pour mieux comprendre la violence des femmes [Reflecting on the impact of socialization to better understand women's violence]. Recherches féministes, 30(2), 257-273.

Dobash, R. P., \& Dobash, R. E. (2004). Women's violence to men in intimate relationships: Working on a puzzle. British Journal of Criminology, 44(3), 324-349.

Gaventa, J., \& Cornwall, A. (2008). Power and knowledge. In P. Reason \& H. Bradbury (Eds.), The Sage handbook of action research: Participative inquiry and practice (2nd ed., pp. 172-189). Sage.

Hesse-Biber, S. N., \& Leavy, P. L. (2007). Feminist research practice: A primer. Sage.

Hulko, W. (2015). Operationalizing intersectionality in feminist social work research: Reflection and techniques from research with equity-seeking groups. In S. Wahab, B. Anerson-Nathe, \& C. Gringeri (Eds.), Feminisms in social work research (pp. 69-89). Routledge.

Joyappa, V., \& Martin, D. J. (1996). Exploring alternative research epistemologies for adult education: Participatory research, feminist research and feminist participatory research. Adult Education Quarterly, 47(1), $1-14$.

Kohler Riessman, C. (1987). When gender is not enough: Women interviewing women. Gender \& Society, 1(2), 172-207. 
Langan, D., \& Morton, M. (2009). Reflecting on community/academic "collaboration": The challenge of "doing" feminist participatory action research. Action Research, 7(2), 165-184.

Maguire, P. (1996). Considering more feminist participatory research: What's congruency got to do with it? Qualitative Inquiry, 2(1), 106-118.

Maguire, P. (2007). Feminist participatory research. In A. M. Jaggar (Ed.), Just methods: An interdisciplinary feminist reader (pp. 417-432). Paradigm.

Mehrotra, G. (2010). Toward a continuum of intersectionality theorizing for feminist social work scholarship. Affilia: Journal of Women and Social Work, 24(4), 417-430.

Miles, M. B., \& Huberman, A. M. (1994). Qualitative data analysis: An expanded sourcebook. Sage.

Mullaly, R. P. (2007). The new structural social work. Oxford University Press.

Neuman, W. L. (2009). Understanding research (4th ed.). Pearson.

Ozanne, J., \& Saatcioglu, B. (2008). Participatory action research. Journal of Consumer Research, 35(3), 1-17.

Ponic, P., Reid, C., \& Frisby, W. (2010). Cultivating the power of partnerships in feminist participatory action research in women's health. Nursing Inquiry, 17(4), 324-335.

Ramazanoglu, C., \& Holland, J. (2002). Feminist methodology: Challenges and choices. Sage.

Reason, P. \& Bradbury, H. (Eds.). (2008). The Sage handbook of action research: Participative inquiry and practice (2nd ed.). Sage.

Reid, C., \& Frisby, W. (2008). Continuing the journey: Articulating dimensions of feminist participatory action research (FPAR). In P. Reason \& H. Bradbury (Eds.), The Sage handbook of action research: Participative inquiry and practice (2nd ed., pp. 93-105). Sage.

Reid, C., Tom, A., \& Frisby, W. (2006). Finding the "action" in feminist participatory action research. Action Research, 4(3), 315-332.

Roy, V., Damant, D., Vu, O., \& Chbat, M. (2019). Perceptions des participantes sur les effets d'unprogramme pour les femmes exerçant de la violence [Women's perceptions of the effects of a program for women who use violence]. Criminologie, 52(1), 277-299.

Samuels, G. M., \& Ross-Sheriff, F. (2008). Identity, oppression, and power. Affilia: Journal of Women and Social Work, 23(1), 5-9.

Whitmore, E. (1994). To tell the truth: Working with oppressed groups in participatory approaches to inquiry. In P. Reason (Ed.), Participation in human inquiry (pp. 82-98). Sage.

\section{Author Biographies}

Holly Johnson, PhD, is associate professor in the Department of Criminology, University of Ottawa. Her research examines criminal justice and social responses to gender-based and structural violence through innovative methodologies.

Catherine Flynn, PhD, is associate professor in the Department of Humanities and Social Sciences at the University of Quebec in Chicoutimi. Her research focuses primarily on violence against women. She is also interested in feminist research processes. 